Res Publica. Revista de Historia de las Ideas Políticas ISSN-e: 1989-6115

\title{
La polis de Dios. El doble poder medieval y una sobrenaturalización de lo político
}

\author{
Matías Daniel Pasqualini*
}

Recibido: 13 de mayo de 2018 / Aceptado: 14 de diciembre de 2018

Resumen. Francisco Bertelloni en "La teoría política medieval entre la tradición clásica y la modernidad" (2010) procura poner en evidencia cómo la transición de la filosofía política clásica a la filosofía social moderna encuentra un momento decisivo en la teoría política medieval, particularmente verificable en La monarquía de Tomás de Aquino, en la medida en que allí tiene lugar una reducción del concepto de polis a oikos. En esta presentación, pretendemos primeramente proponer nuestra reinterpretación de la génesis histórica del doble poder medieval; en segundo lugar, reconstruir la argumentación del autor en torno a la mencionada reducción; por último, sugerir una hipótesis de lectura de $L a$ monarquía, complementaria a la tesis del autor, en referencia a un posible desplazamiento a un plano sobrenatural del contenido político inherente a la concepción clásica.

Palabras clave: Iglesia imperial; poder espiritual; poder temporal; teoría política clásica; teoría política medieval

\section{[en] The polis of God. Double medieval power and supernaturalization of politics}

\begin{abstract}
Francisco Bertelloni in "La teoría política medieval entre la tradición clásica y la modernidad" (2010) seeks to show how the transition from classical political philosophy to modern social philosophy finds a decisive moment in medieval political theory, particularly verifiable in On Kingship of Thomas Aquinas, since there occurs a reduction of the concept of polis to oikos. In this presentation, we seek first to propose a reinterpretation of the historical genesis of the medieval double power; secondly, to reconstruct the author's argument on the abovementioned reduction; finally, to suggest an interpretation of On Kingship, complementary to the thesis of the author, in reference to a possible displacement to a supernatural plane of the political content inherent to the classic conception.
\end{abstract}

Keywords: Classical politics; Imperial Church; Medieval politics; Spiritual power; Temporal power.

Sumario. 1. Génesis histórica del doble poder. 2. Reducción de polis a oikos. 3. Sobrenaturalización de lo político. 4. Comentarios finales.

Cómo citar: Daniel Pasqualini, M. (2019). La polis de Dios. El doble poder medieval y una sobrenaturalización de lo político, en Res Publica 22.1, 1-14.

\footnotetext{
* Universidad Nacional de Rosario, Argentina. matiaspasqualini@gmail.com
} 


\section{Génesis histórica del doble poder}

Los momentos conceptuales de la teoría política medieval traducen instancias históricamente constituidas ${ }^{1}$. No puede entonces dilucidarse acabadamente la compleja relación teórica entre poder temporal y espiritual sin apelar a la génesis de sus instancias históricas respectivas. Proponemos a continuación una sumaria reconstrucción de este proceso. Es lugar común considerar que la condición que mejor caracteriza al formato de gobierno del medioevo occidental es aquella cesura entre dos poderes opuestos: uno definido como espiritual, representado por el papado en cuanto cabeza de la Iglesia de Roma; otro temporal, representado sucesivamente por el Imperio Carolingio y el Sacro Imperio Romano Germánico. Nos interesa mostrar en esta reconstrucción que ambas esferas no son poderes independientes sino que constituyen un sistema más o menos articulado. La característica común de ambas instancias del sistema es su pretensión de alcance universal sobre las iglesias y reinos de carácter local. La tensión entre ambas instancias del sistema proviene de la falta de un acuerdo preciso sobre sus jurisdicciones respectivas desde el inicio mismo de su relación. Dicha tensión alcanzó su clímax con ocasión de la reforma gregoriana que llevará al papado a disputar las investiduras al Sacro Imperio.

Si bien es claro que cada una de las instancias del sistema buscó avanzar sobre la otra (v. gr. deposición de Enrique IV por Gregorio VII en 1080; múltiples nombramientos de antipapas por parte de los emperadores), proponemos que ambas instancias forman un solo sistema en la medida en que se sostienen recíprocamente. Cada parte del mismo contiene virtualmente a la otra: nótese que al Imperio se le añade la adjetivación "sagrado" y la iglesia que pretende alcanzar un poder universal es precisamente aquella heredera de la Iglesia imperial antigua con sede en Roma. Cada una de las instancias del sistema, Iglesia e Imperio, contenía de modo implícito lo que era explícito en la otra: esto explica la aparente paradoja de que cada instancia pretenda el dominio sobre la otra como si ellas fueran potencias rivales y al mismo tiempo cada parte legitimaba a la otra en su pretensión de universalidad. De hecho, el triunfo definitivo de la Iglesia sobre el Imperio con la consolidación y explicitación teórica de la teocracia pontificia en Unam sanctam, en el culmen del medioevo hacia el siglo XIII, representó también un quiebre del formato de gobierno medieval que no tendrá retorno. Nos encontramos en el medioevo occidental ante una Iglesia con características de imperio y un Imperio con características de iglesia, constituyendo ambas un solo doble poder. Aunque parezcan dos totalidades perfectas en sí mismas, ellas forman un único y mismo sistema. A efectos de simplificar, en adelante llamaremos a todo el sistema la Roma medieval.

Nos preguntamos ahora cómo fue posible que la Roma medieval llegara a esta condición bicéfala. La respuesta no la encontramos en la misma Edad Media, habrá que remontarse para ello a la antigua Iglesia imperial ${ }^{2}$. La clave está en la apropiación que la Roma antigua hizo del cristianismo en el siglo IV. Constantino I dio estatuto legal a la religión cristiana en 315 y Teodosio I adoptó el cristianismo niceno

\footnotetext{
Cf. F. Bertelloni, "La teoría política medieval entre la tradición clásica y la modernidad", en P. Roche Arnas (ed.), El pensamiento político en la Edad Media, Madrid, Fundación Ramón Areces, 2010, pp. 17-40, aquí p. 17 ss.

2 "Se tiende cada día más a admitir que las bases de las concepciones e ideas fundamentales acerca de las formas de gobierno se establecieron en el bajo Imperio romano, durante los siglos IV y V" (W. Ullmann, Historia del pensamiento político en la Edad Media, Barcelona, Ariel, 1999, p. 21).
} 
como religión oficial del Imperio en 380. El emperador romano, de antiguo jefe de la religión estatal, dotó al difuso movimiento cristiano con una estructura de gobierno. No se trató de una estructura ad hoc, sino que la misma estructura administrativa del Imperio se convirtió en la estructura de gobierno de la Iglesia cristiana. En el mismo sentido en que desde antiguo el culto religioso era administrado por el Estado, la Iglesia cristiana, bajo la tutela de Roma, debió incorporarse a su estructura de gobierno, adquiriendo así un ordenamiento jurídico formal del que antes carecía ${ }^{3}$. A modo de ejemplo, cabe mencionar que la intervención del emperador fue clave en la resolución del conflicto entre ortodoxia y arrianismo. De hecho, fue Constantino quien convocara el Concilio de Nicea en 325 a tal efecto ${ }^{4}$. Con la fundación de Constantinopla y la posterior división del Imperio, este único poder, indiferenciadamente religioso y temporal, quedará consolidado en oriente hasta el siglo XV. La situación en la Roma occidental sería diferente: progresivamente debilitada por las incursiones de los pueblos germánicos y otros factores, la figura del emperador occidental será cada vez menos significativa. En proporcional medida, la figura del papa, titular de la Iglesia de Roma, irá acrecentando su autoridad y ocupando simbólicamente el nicho que la devaluada figura del emperador occidental iba liberando. En este punto, la crónica del papa León I Magno en 452 negociando con Atila en cuanto representante de Roma resulta particularmente ilustrativa.

Se suele ver en la caída del emperador romano en 476 el fin del Imperio occidental. De acuerdo a la interpretación que proponemos, esta caída debe ser convenientemente relativizada. Ciertamente es tal en cuanto a la desaparición temporaria de una estructura de gobierno efectiva de alcance universal, estructura que a la sazón estaba profundamente debilitada. Sin embargo la caída no es tal en cuanto que el capital simbólico para fundamentar un poder universal se conserva en la figura del papa, luego de la caída del antiguo Imperio. De aquí en adelante asistiremos al lento proceso de reconstrucción del poder imperial en occidente en torno a la figura papal. Señalemos los principales momentos de este proceso histórico. Primeramente, debe mencionarse el progresivo distanciamiento del papado respecto del emperador oriental, tal como se pondría en evidencia en el pontificado de Gregorio I Magno. Ya San Agustín, ante la decadencia del Imperio occidental, no había visto en el oriental su legítimo sucesor con derecho al gobierno de la Iglesia sino que apela a una mística Ciudad de Dios. Dicho distanciamiento puede interpretarse como un síntoma de la vocación imperial del papado: en ese sentido, el Imperio oriental se convierte en un poder rival de la Iglesia de Roma. En este contexto aparece por primera vez una elaboración teórica de los dos poderes. El papa Gelasio I dirigirá en 494 una muy relevante misiva al emperador Anastasio I, donde afirma que a la par del poder real existe un poder sacerdotal: la Ciudad de Dios cobra visibilidad en la Iglesia de Roma. Como puede verse, apelar a la existencia de dos poderes es una estrategia por la cual el papado procura legitimar su propia pretensión de poder en un contexto en el que todavía no podía desconocer un poder universal ya constituido en la figura

"El decreto dictado en el año 380 por los emperadores Valentiniano II, Graciano y Teodosio I, en virtud del cual la religión cristiana quedaba proclamada religión oficial del Imperio, no era simplemente un paso de significación histórica universal, sino el instrumento apto para que el Papado (la Iglesia de Roma) quedara consagrado como institución de gobierno" (W. Ullmann, op. cit., p. 22).

4 Pueden confrontarse alusiones a la historia de la Iglesia en J. Lortz, Historia de la Iglesia, vol. I, Madrid, Cristiandad, 1982. 
del emperador de oriente 5 . Finalmente, el papa llegará a desafiar abiertamente la autoridad imperial oriental cuando, aprovechando el capital simbólico en su figura condensado, proceda al nombramiento de un emperador para occidente en 800. Los dos poderes, antes necesariamente antagonistas en cuanto uno era oriental y el otro occidental, se resuelven ahora en dos poderes occidentales que, como hemos sugerido anteriormente, constituyen un sistema. Aunque hacia el 800 el papa además de titular de la Iglesia de Roma era ya un señor territorial -la donación de Pipino había tenido lugar en el 756- no tenía a su alcance autoproclamarse emperador. Entretanto, el rey franco había expandido su poder hasta dominar el escenario occidental. Una alianza entre el papa y el rey franco permitiría eventualmente rehabilitar en occidente al antiguo Imperio romano: Roma occidental llega a su etapa medieval como un sistema necesariamente bicéfalo, entretanto la Roma oriental se mantiene como un único poder. Con esto, las condiciones para el llamado Cisma de Oriente ya estaban dispuestas: sólo habría que esperar una nueva oleada expansionista de la Roma occidental cuando la reforma gregoriana a partir del siglo XI.

La clave es que la alianza entre papado y los reinos germánicos que oportunamente fueron sede imperial era confusa: cada una de las partes creía haber obtenido más derechos de los que había cedido, y las atribuciones del antiguo emperador romano no estaban claramente distribuidas entre ellos. Quizás la imprecisión del contrato fue su condición de posibilidad: cada parte pudo así mantener la ilusión de heredar el poder universal de la antigua Roma, siendo que en los hechos cada parte necesitaba de la otra para aspirar a tal presunción. La complejidad de esta relación queda ilustrada por el hecho de su mutua competencia pero, al mismo tiempo, mientras duró la Roma medieval, cada parte supo cuál era el límite de sus exigencias más allá del cual comprometería el equilibrio del sistema: el papa concurriría oportunamente a la correspondiente unción imperial del heredero; el emperador atendería puntualmente al auxilio militar del papa. Todavía en el siglo XV, cuando el papado entró en una grave crisis, el llamado Cisma de occidente, fue el emperador quien tuvo la autoridad suficiente para convocar el Concilio que recompondría la unidad de la Iglesia occidental (Concilio de Constanza).

Sin embargo, el inestable equilibrio entre las dos partes del sistema de la Roma medieval comienza a desvirtuarse cuando una de ellas, el papado, emprende un proceso de reforma que revertiría el cesaropapismo antiguo en teocracia pontificia. Se trata del programa al que aludimos anteriormente: la llamada reforma gregoriana, dado que Gregorio VII fue su mentor. El primer paso fue el control de las investiduras eclesiásticas, anteriormente en manos del emperador. Pero la reforma gregoriana tuvo un impacto de más largo alcance: fue más allá de la mera libertas ecclesiae, rompió el equilibrio de los dos poderes y logró el sometimiento del Imperio a la Iglesia de $\mathrm{Roma}^{6}$. Por primera vez el papado adquiere el poder suficiente para convocar

\footnotetext{
“Agustín no mira a Bizancio como paradigma opuesto a la Roma pagana. Su modelo sustitutivo de origen divino de la vieja Roma pagana no es la nueva Roma imperial cristiana, sino la civitas Dei, entendida como cuerpo místico y ciudad espiritual que no es de este mundo" (F. Bertelloni, op. cit., p. 21). Este autor coincide con Udina en reinterpretar la tesis de Arquillière: el llamado agustinismo político no consiste en establecer una subordinación del poder temporal al religioso, ya que en el momento no estaba aún constituido un doble poder. La civitas Dei agustiniana no constituye una estructura de poder sino una apelación a una instancia trascendente. Cf. J. M. Udina, "De Gelasio (I) a Gelasio (II), o de Iglesia mendigo a Iglesia príncipe", en P. Roche Arnas (ed.), El pensamiento político en la Edad Media, Madrid, Fundación Ramón Areces, 2010, pp. 65-93, aquí p. 69.

6 El hecho histórico de la humillación de Enrique IV ante Gregorio VII en Canossa ilustra este hecho (cf. J. Le
} 
un concilio ecuménico en 1123, ya que todos los anteriores habían sido convocados por el emperador oriental. El posterior Inocencio III llegará a ser virtualmente el verus imperator ${ }^{7}$. El papa será el único depositario de la plenitudo potestatis ${ }^{8}$. La teoría política en este contexto desarrollará la idea de que la autoridad imperial es una delegación papal ${ }^{9}$. En estas condiciones, la Iglesia de Roma se autoproclamó canon de la Iglesia universal, expresión visible y normativa de la Iglesia católica ${ }^{10}$. Los impulsos expansionistas de la Roma medieval llegarán más allá de los límites de occidente. Los cruzados en su paso a Palestina fundarán un efímero Imperio latino en la cismática Bizancio. La reacción del Sacro Imperio será fatal para la pervivencia del sistema de poder medieval: decidió desacralizarse cuando los electores dejaron fuera al papa del proceso de elección del emperador en 1356.

Cabe aclarar que con esta tesis no pretendemos sostener una continuidad lineal y simple entre la Roma antigua y medieval como mero retorno de lo mismo, ni mucho menos desconocer la originalidad que el cristianismo aporta a la historia de occidente. Sin la irrupción del cristianismo el medioevo no podría haber desarrollado aquel peculiar sistema de poder doble. En cualquier caso, la continuidad lineal entre la Roma antigua y la medieval se verifica solamente en oriente, conservándose allí en la única figura del Basileus las potestades temporal y espiritual de acuerdo a la usanza antigua. Ciertamente, el cristianismo introduce en la historia una tensión entre un orden inmanente y otro trascendente que es condición de posibilidad del desdoblamiento del poder en un sistema. Sin embargo, dicha posibilidad pudo actualizarse sólo en occidente a partir de la caída de la Roma occidental antigua. De aquí que el modelo de gobierno romano se puede recuperar en la Edad Media sólo engarzado en la polarización introducida por el cristianismo entre una esfera inmanente y otra trascendente. Asimismo, el gobierno universal encarnado en el sistema de doble poder político Iglesia-Imperio coexiste perfectamente con una es-

Goff, La Civilización del occidente medieval, Barcelona, Paidós, 1999, p. 80). El uso del documento apócrifo Donatio Constantini en este contexto es particularmente revelador: según este texto, el mismo Constantino habría entregado la parte occidental del Imperio al papa Silvestre I, reconociendo su dignidad, antes de migrar a oriente (http://www.thelatinlibrary.com/donation.html).

7 Otro hecho significativo que pinta los divergentes procesos de occidente y oriente es el llamado concilio de unión en Florencia (1439) donde los orientales buscan la unión con occidente a causa del avance turco. Quien se sentó a negociar la unión frente al papa occidental no fue el patriarca de Constantinopla sino el mismo emperador oriental. El papa llegó en el culmen de su poder a tener para los orientales un lugar paralelo al del emperador oriental, mientras que éste entendía su propio lugar como una continuación directa y efectivamente ininterrumpida con los antiguos emperadores romanos (cf. J. Lortz, op. cit., p. 523).

8 Cf. A. Winroth, "The legal underpinnings" en M. Rubin y W. Simons (eds.), The Cambridge History of Christianity, Vol. 4 Christianity in Western Europe c. 1100-c. 1500, Cambridge University Press, 2009, pp. 89-98, aquí p. 95. Según Berman y Prodi, la aplicación del proyecto gregoriano comportó una verdadera revolución en la historia jurídica y constitucional (Cf. C. Gallego, Pastorado, soberanía y salvación: un análisis del poder gubernativo y jurídico en el cristianismo medieval (siglos XI-XIII), Madrid, 2018, pp. 110-112).

$9 \quad$ Escribe Gilson haciendo alusión a la teoría de las dos espadas en pleno proceso de reforma gregoriana: "Toda esta situación está dominada por un hecho: la distinción de los dos órdenes -temporal y espiritual- es una distinción interior a la Iglesia. En este edificio complejo, cuya piedra angular es el poder espiritual del Papa, el muro temporal sólo se mantiene en pie gracias a la autoridad papal" (E. Gilson, La filosofía en la Edad Media, Madrid, Gredos, 1999, pp. 326-327).

10 Dictatus Papae, documento atribuido a Gregorio VII como expresión de su programa de gobierno, establece en su punto 26: "Que aquél que no está en paz con la Iglesia romana no será considerado católico". En el 12: "Que le es permitido [al papa] deponer a emperadores". Estas dos citas bastan para ilustrar el proyecto de dominio sobre la Iglesia universal y sobre el Imperio llevado a cabo por el titular de la Iglesia de Roma (http://sourcebooks. fordham.edu/source/es-g7-dictpap.asp). 
tructura capilar de gobierno pastoral de carácter económico, como administración de la gracia en los sacramentos por medio de la llamada "cura de almas", sin que esto constituya una objeción a la tesis de una relativa continuidad entra la Roma antigua y la medieval. Precisamente, síntoma del restablecimiento progresivo del aparato de gobierno de la Roma antigua es el agudo proceso de juridización de la administración de la gracia que se verifica particularmente con ocasión de la revolución gregoriana ${ }^{11}$. La innovación gregoriana no es reforma ni restauración de lo cristiano antiguo como ella misma quiere presentarse, sino restauración de lo romano antiguo; es decir, constituye de alguna forma el restablecimiento del aparato administrativo romano ${ }^{12}$. En cierto sentido puede considerarse una revolución ya que provoca en un mismo proceso la libertad de la Iglesia respecto del tejido feudal altomedieval, el debilitamiento y eventual quiebre del sistema de doble poder, la introducción de la teocracia pontificia, la centralización de la administración y la sistematización del derecho ${ }^{13}$.

A modo de conclusión parcial, decimos que sólo podemos entender el complejo sistema de doble poder vigente en el medioevo occidental cuando comprendemos que la Roma medieval es una virtual continuación de la Roma antigua ${ }^{14}$, donde papa y emperador se distribuyeron y compitieron por las atribuciones políticas y religiosas del antiguo emperador romano. No es suficiente con aceptar que el papa medieval es un simple sucesor del apóstol Pedro con súbitas pretensiones de poder. El papa medieval es virtual heredero del poder progresivamente acumulado por el emperador romano. Dicho de otro modo, en el papado medieval subsistirá la figura del antiguo emperador romano. Es éste quien heredará el título imperial pontifex maximus. La aparición en el mundo antiguo de una religión universal, en el sentido que podía propagarse por naciones diferentes dado su apoliticismo ${ }^{15}$, fue aprovechada por las necesidades de un poder imperial que buscaba asegurar su unidad interna. La constitución histórica y la respectiva teorización de los dos poderes no fue sino una estrategia temporaria del poder imperial. El momento culminante del proceso señala paradójicamente el comienzo del fin: cuando el papado medieval logra reabsorber todas las atribuciones imperiales que había temporariamente confiado a su poder espejo, el papa medieval coincide con el emperador antiguo, el cesaropapismo se revierte en teocracia y el poder temporal se reduce al espiritual. La Edad Media, más aún, todo el ciclo de Roma, se había agotado. La condición de posibilidad de la constitución de un poder universal había cesado. El siglo XIV señalará el ocaso de

11 Debe hacerse notar que recién en este estadio histórico la noción de Corpus Mysticum se corre de su original referencia al sacramento eucarístico para pasar a significar a la sociedad visible de la Iglesia (cf. E. Kantorowicz, The King's Two Bodies. A Study in Medieval Political Theology, Princeton University Press, 2016, p. 203). La juridización del gobierno propiamente pastoral es sin duda condición de posibilidad de dicho desplazamiento semántico. La parroquia medieval representará precisamente una institución de síntesis: unidad pastoral y jurídica a la vez (cf. Gallego C., op. cit., p. 98).

12 Señala Berman que hasta 1075 el derecho en occidente era todavía germánico (cf. H. Berman, "The Influence of Christianity upon the development of Law”, en Oklahoma Law Review 86, 1959, pp. 86-101, aquí p. 93). Sólo la innovación gregoriana restablecerá plenamente el derecho romano en occidente.

13 Para un análisis detallado de este proceso sugerimos ver el trabajo de C. Gallego, op. cit. pp. 108-134.

14 Bertelloni cita en este punto a Hobbes: "Si un hombre considera el origen de este gran dominio eclesiástico percibirá con facilidad que el Papado no es sino el fantasma del fallecido Imperio romano, que se sienta coronado sobre su tumba. Porque así brotó súbitamente el Papado de las ruinas de ese poder pagano [...]. Cfr. Leviatán, cap. XLVII" (F. Bertelloni, op. cit., p. 22).

15 Cf. H. Arendt, La condición humana, Buenos Aires, Paidos, 2009, p. 79. 
Roma como potencia temporal. El XVI, con la reforma protestante, indicará su ocaso incluso como potencia espiritual.

Para ser más precisos y poner así a resguardo de una posible objeción a nuestra interpretación de la génesis del doble poder como continuidad entre la Roma antigua y la medieval debemos decir que la mentada continuidad se verifica solamente de modo estricto en el punto preciso en que el poder papal reabsorbe por completo la potestad espiritual compartida con el poder imperial, causando simultáneamente la eventual secularización del poder temporal y una plena mundanización o visibilización de la estructura de la Iglesia. El cristianismo había introducido temporalmente en occidente aquella tensión entre lo inmanente y lo trascendente que constituyó sólo una condición de posibilidad del sistema de doble poder. El doble poder concentrado en la figura del emperador romano antiguo se escindió en dos poderes espejo recién luego de su caída. La continuidad entre la Roma antigua y la medieval fue primero solamente latente y simbólica hasta que progresivamente se actualiza y llega a la final supresión del sistema de doble poder en el instante en que la revolución papal alcanza su pleno triunfo, extinguiendo así las condiciones que hacen posible el ejercicio del poder en la era cristiana medieval y dando por ello mismo fin al completo "ciclo de Roma". Tanto el Imperio carolingio en manos de los francos como el Sacro Imperio en manos de los sajones pretendieron ser una reactualización del sistema administrativo romano antiguo. Pero finalmente será la misma Iglesia de Roma quien logre llevar a su máxima expresión, aunque fugaz, aquel viejo anhelo medieval de raíces antiguas: el Imperio cristiano. Será la juridización del gobierno pastoral y no la asunción de funciones pastorales por parte del poder temporal el modelo que triunfe y que complete el ciclo de la Roma imperial. La revolución gregoriana terminará produciendo a la postre y como consecuencia no prevista una secularización del poder temporal que es causa remota del Estado moderno despolitizado.

\section{Reducción de polis a oikos}

Tenemos presentado el marco histórico en el que se inscribe el problema teórico en el que a continuación queremos adentrarnos. Corresponde ahora reponer esquemáticamente la argumentación de la citada ponencia de Bertelloni, para posteriormente presentar nuestra propuesta de lectura de La monarquía de Tomás de Aquino. Recordemos que el propósito último del autor en su ponencia es mostrar que en la teoría política medieval se verifica una ruptura respecto de la teoría política clásica (particularmente aristotélica) y un anticipo de la moderna idea de un Estado despolitizado, simple garante del sostenimiento de relaciones económicas entre los individuos.

Primeramente, el autor encuentra que todas las teorías políticas medievales tienen que habérselas con la cuestión de la relación entre los dos poderes. Los teóricos medievales resuelven este problema de diferente manera: unos sosteniendo cierta autonomía específica y complementariedad de los poderes, otros procurando una asimilación de uno en el otro. Ejemplo de la primera solución es la de Tomás de Aquino; de la reducción de dos a uno son ejemplos: Marsilio de Padua reduciendo el espiritual, Egidio Romano el temporal. Pero todos convergen en dos puntos: la necesidad de interpretar la tensión inherente a un doble poder y una nueva conceptualización del poder temporal. Este último punto es aquél donde se focaliza el 
interés de Bertelloni, porque allí opera la antedicha ruptura con lo clásico y anticipo de lo moderno. A nosotros nos interesará mostrar que hay una relación al menos de conveniencia entre la constitución histórica de un doble poder y el fenómeno teórico de la despolitización del concepto del poder temporal.

Los autores medievales recuperan de los clásicos un presupuesto que proviene del campo ético, la idea de que al hombre corresponde un fin natural. Con el propósito de fundamentar teóricamente el doble poder de hecho constituido, proponen asimismo un desdoblamiento teleológico. La teoría política medieval deberá postular un fin sobrenatural del hombre junto con el natural. Evidentemente, situar el fin natural como intermedio para un fin sobrenatural último será una manera de legitimar una subordinación del poder temporal bajo el espiritual, en la medida en que se considera que cada uno de los poderes es responsable de conducir a los hombres a fines diferentes pero subordinados.

Centrada nuestra atención en el esfuerzo teórico medieval en torno al problema del doble poder, y sobre el presupuesto del doble fin, junto con el autor ponemos ahora el foco en el procedimiento medieval para "definir el status ontológico del poder temporal"16. Nuestro autor seguirá aquí de cerca el análisis que Habermas hace de La monarquía de Tomás de Aquino en Theorie und Praxis. El filósofo alemán denuncia un vaciamiento del contenido original del orden político tal como lo pensaban los griegos. Dicha desnaturalización de la polis tiene lugar de dos modos. En primer lugar, la polis clásica no responde solamente a la satisfacción de las necesidades materiales de los individuos sino que tiene una meta más alta, de cuño ético-racional, meta que supone el desarrollo de la virtud y la consecución de la felicidad. Entretanto, la monarquía medieval parece estar acotada a la simple administración de los medios materiales y el establecimiento de la paz social ${ }^{17}$. La segunda parece vaciada del contenido propiamente político de la primera, es decir, carece del sentido de la polis como comunidad política que concurre al bien común. Aristóteles nunca aceptaría la idea moderna de un orden social puesto en función de los intereses meramente particulares. En la política clásica, el derecho público tiene su especificidad y autonomía respecto de la esfera privada. En contraste, la monarquía medieval tiene el carácter formal de una estructura que coordina las búsquedas individuales del bien particular, con claro sabor moderno. En segundo lugar, las relaciones de dominio en la polis no hacen abstracción de la racionalidad de los ciudadanos y el ejercicio del poder requiere del consentimiento de los mismos. Entretanto, en la monarquía medieval las relaciones de dominio se han vuelto despóticas: el ciudadano se ha reducido a súbdito. Estas relaciones de dominio se asemejan a las que en el contexto de la teoría política clásica el paterfamilias ejerce a nivel doméstico sobre sujetos no libres (esclavos) o no plenamente libres (mujer e hijos). Precisamente, esta asimilación que Habermas registra de lo político a lo doméstico en La monarquía de Tomás de Aquino le permite establecer su tesis de una reducción de polis a oikos que opera en la teoría política medieval como anticipo de la filosofía social moderna: las relaciones políticas se convierten a partir del medioevo en relaciones económicas ${ }^{18}$.

\footnotetext{
F. Bertelloni, op. cit., p. 24.

Tomás de Aquino, La monarquía, Trad. L. Robles, Barcelona, Altaya, 1997, p. 77.

18 Preferimos no omitir la aclaración de que la palabra castellana economía proviene de la griega oikos y que en el contexto antiguo tenía un sentido acotado a lo doméstico.
} 
La tesis de Habermas depende de dos constataciones: el mismo Aristóteles, en su análisis de la monarquía, caracteriza esta forma de gobierno como régimen análogo al económico, razón por la cual no es considerada por Aristóteles como la forma de gobierno óptima atendiendo a la naturaleza de la polis ${ }^{19}$. El otro hecho es que Tomás de Aquino efectivamente optó por la monarquía como mejor forma de gobierno para las jurisdicciones locales. Dado que Tomás conoce la política clásica, cuando opta por la monarquía no puede ignorar que está concibiendo el dominio temporal según el modelo del oikos y no según el modelo de la polis. No obstante, Bertelloni no deja de señalar un hecho que parece poner en cuestión la tesis de Habermas, o, si ésta es correcta, implicaría una ambigüedad en el pensamiento de Tomás. Cierto pasaje de La monarquía parece tributar una dependencia del pensamiento de Tomás respecto de la teoría clásica precisamente en el punto en que Habermas quiere mostrar una ruptura, en la medida en que pretende fundamentar la vida política en la virtud.

Habermas encuentra apoyo para su tesis en la traducción que Tomás hace del zoon politikon aristotélico: Tomás traduce politikon por la voz latina sociale: "homo naturaliter est animal sociale" ${ }^{20}$. La reducción del orden político a simple orden social que se esconde detrás de la traducción de Tomás delata una nueva concepción del orden temporal que rompe con la concepción clásica, y según Bertelloni siguiendo a Habermas, anticipa la concepción moderna. El autor se atreve a afirmar que la devaluación tomista de lo político y su reducción a mero orden económico tienen el carácter de "protoburgués" 21 . La interpretación que nuestro autor hace de la tesis de Habermas procura poner en evidencia una deliberada intención de Tomás por despolitizar el orden temporal. Por qué Tomás procede de esta manera escapa a la tesis de Habermas. Éste se limita a constatar el hecho y a apuntar un fragmento moderno en el corazón de la teoría política medieval. La hipótesis de lectura de La monarquía que a continuación sugeriremos pretender cubrir ese interrogante.

\section{Sobrenaturalización de lo político}

Desde nuestro punto de vista el análisis de Habermas recogido por Bertelloni admite una tesis complementaria, en la medida en que omite una referencia del componente teológico de la teoría política de Tomás. Su teoría política no es exclusivamente filosófica como la aristotélica. El naturalismo clásico queda en el pensamiento medieval articulado con un componente teológico. El mismo Habermas había reconocido el desdoblamiento teleológico que opera en el pensamiento medieval, sin embargo, al menos según la versión que nos ofrece Bertelloni, no repara en estudiar si alguno de los componentes de la teoría política clásica, en lugar de simplemente desaparecer, queda desplazado a un plano sobrenatural.

\footnotetext{
19 "Pero hay una quinta clase de realeza, que se da cuando un único gobernante tiene la suprema soberanía sobre todas las materias y cuestiones, a la manera como cada raza y cada ciudad es soberana en sus asuntos propios; esa monarquía está en la misma categoría y rango que el gobierno del señor sobre su familia toda, ya que, igual que el gobierno del señor, es una especie de monarquía en la casa, así la monarquía absoluta es un señorío doméstico sobre una ciudad, sobre una raza o sobre varias razas" (Aristóteles 1285b/1286a).

20 F. Bertelloni, op. cit., p. 27.

21 Ibidem, p. 40.
} 
Nuestra hipótesis de lectura precisamente propone vincular el fenómeno teórico de la despolitización de la polis con el fenómeno histórico de la formación de un sistema de doble poder en el medioevo: el componente político desaparece del orden temporal en el pensamiento medieval porque queda desplazado al orden espiritual, cumpliendo la función de legitimar la existencia del sistema de doble poder históricamente constituido en la Roma medieval. Sin la mediación de una interpretación teórica del sistema de doble poder medieval difícilmente hubiera tenido lugar aquella despolitización de las relaciones de poder que heredaría la modernidad en su filosofía social. El punto particularmente interesante es que el componente sobrenatural postulado en la teoría medieval no es una extravagancia teológica, de índole completamente diversa a lo ya establecido en la naturaleza de la polis clásica, sino que es un componente de la misma desplazado a y apropiado por un orden que ahora es trascendente y universal.

En la visión clásica, el fin último del hombre, de carácter ético-racional, i. e. la vida virtuosa y la consecución de la felicidad, tiene carácter inmanente y natural y por ello mismo ha de resolverse en la polis. La unidad política natural en Aristóteles es la polis, comunidad perfecta y autosuficiente. Por ello mismo es una realidad clausurada y no es integrable de suyo en un orden universal. Necesariamente la polis tiene carácter local y concreto. Por otro lado, en la visión medieval se hace necesario dotar de contenido al sistema de doble poder universal de hecho constituido y articular a su vez a las unidades sociales locales. Por ello, el procedimiento medieval fue romper la unidad natural de la polis al desplazar la satisfacción del fin ético-racional a un orden político universal. Las unidades sociales locales, imperfectas, necesitan articularse en un orden superior y universal para llevar a los individuos al cumplimiento de su fin último. A las unidades sociales inferiores, monarquías locales, se les asigna un fin intermedio. Se les dota de un contenido sólo parcial respecto del contenido total de la polis clásica: ese contenido es económico, fin intermedio subordinable al fin último. El monarca medieval, como lo hará el individuo moderno, vela solamente por el derecho particular. El derecho público queda tutelado por el poder universal, el sistema Iglesia-Imperio en que consiste la Roma medieval.

Dado que Tomás de Aquino era consciente, cuando optó por la monarquía como mejor forma de gobierno, de que estaba privilegiando un modelo económico de poder, no nos es lícito pensar que la aparente desaparición del componente político en la estructura del poder temporal según Tomás sea una omisión inadvertida o una deliberada eliminación. Tomás tuvo que situar el componente político de la polis clásica en algún otro momento de su teoría política. Hacia ese momento apunta nuestro interés: un poder alternativo vela por el fin político del hombre, quedando por ello mismo legitimado. Dado que ahora ese fin político se ha puesto fuera de la naturaleza, se ha sobrenaturalizado, tal poder será considerado espiritual:

Pero hay un bien extrínseco al hombre, incluso cuando se encuentra en la vida mortal, o sea, la felicidad última que se espera alcanzar con la visión de Dios después de la muerte... Por eso el hombre cristiano... necesita otro cuidado espiritual por medio del cual se dirija al puerto de la salvación eterna; este cuidado es mostrado a los fieles por los ministros de la Iglesia de Cristo ${ }^{22}$.

22 Tomás de Aquino, op. cit., p. 70. 
Ese ámbito ya no es susceptible de análisis científico como concebían los clásicos, sino teológico: lo político en Tomás se ha "eclesiologizado". El fin último del hombre, ahora sobrenatural, encuentra su satisfacción en la Civitas Dei, en la Polis de Dios, es decir, la Iglesia. Repárese que en el siglo XIII, a diferencia del tiempo de Agustín de Hipona, cuando hablamos de Iglesia como Civitas Dei hacemos también referencia a una estructura administrativa y jurídica formal. El poder espiritual plenamente visibilizado en el papado queda así en último término justificado por esta apropiación de una finalidad ético-racional que en la teoría política clásica era natural y resuelta en la polis administrada por el poder temporal. Como propusimos anteriormente, las monarquías en Tomás no pueden ser autosuficientes como las polis clásicas. Deben estar abiertas a un perfeccionamiento último por su integración en la Polis de Dios, integración visibilizada en su subordinación al poder universal del sistema Iglesia-Imperio de la Roma medieval:

Luego así el ministerio del reino, al encontrarse separado lo espiritual de lo terreno, ha sido encomendado no a los reyes de la tierra sino a los sacerdotes y principalmente, al Sumo Sacerdote, sucesor de Pedro, Vicario de Cristo, el Romano Pontífice, del que todos los reyes del pueblo cristiano deben ser súbditos, como del mismo Señor Jesucristo. Así pues, como ya se afirmó, aquellos a los que pertenece el cuidado de los fines anteriores y la dirección del imperio deben subordinarse a aquel que tiene el cuidado del último fin $^{23}$.

El carácter instrumental y contingente del Estado según la concepción medieval, de acuerdo a lo señalado por Habermas en su análisis, queda explicado por el hecho de que en ella la comunidad humana, i. e. su dimensión política, se realiza sobrenaturalmente. En la medida en que el hombre naturalmente es sólo individuo sociable y busca su solo bien, el reino aparece como un artilugio temporal para coordinar esas búsquedas conjurando el conflicto y estableciendo la paz social. Llevar a los hombres a la comunidad política universal, integrarlos en una Iglesia de proyección trascendente, será obsequio divino vehiculizado por la estructura del poder universal de la Roma medieval.

La hipótesis que sugerimos, si es correcta, resuelve también la aparente debilidad de la tesis habermasiana a que nos referimos anteriormente, cuando el estudioso alemán constataba cierta ambigua dependencia de Tomás respecto del pensamiento clásico en cuanto señalaba que el sentido del orden temporal no podía ser el simple vivir sino el buen vivir, es decir, la vida virtuosa. La solución pasa por considerar que la vida virtuosa no queda excluida de la concepción medieval, sino que el buen vivir ha sido espiritualizado y proyectado a un plano trascendente. La vida virtuosa es un medio en la tierra para llegar a la visión de Dios en el cielo.

Es notable cómo los aspectos de la polis clásica que Habermas echa de menos en la teoría política medieval aparecen convenientemente proyectados y reciclados, en términos teológicos, a un plano a la vez trascendente y universal, en el mismo texto en que el filósofo ha centrado su análisis: La monarquía de Tomás de Aquino. Habermas deploraba la pérdida del gobierno republicano de la polis, gobierno de iguales para iguales. Pues bien, en la sublimación teológica de la polis, los miembros de la comunidad universal sobrenatural son igualados entre sí, considerados "hijos de Dios" y adquieren todos ellos la condición de "reyes y sacerdotes":

$23 \quad$ Ibidem, pp. 72-73. 
Pero como el hombre no consigue el fin de la visión divina por su virtud humana, sino por favor divino... no pertenece al régimen humano, sino al divino, conducirlo a su último fin [...] Un régimen de este tipo es propio de aquel rey que no es solamente un hombre, sino Dios, o sea, el Señor Jesucristo, que convirtiendo a los hombres en hijos de Dios, los introduce en la gloria del cielo... Y, lo que es más, todos los fieles en Cristo, en cuanto miembros suyos, son llamados reyes y sacerdotes $^{24}$.

Una posible objeción es que esta hipótesis se aplica sólo al poder temporal local y no al poder temporal universal. Pero recuérdese que el poder temporal universal forma un sistema con el poder espiritual universal. Más aún, incluso los teóricos que le reconocen autonomía, como Tomás, lo piensan de algún modo funcional al poder espiritual universal. En la particular configuración bajomedieval, el poder temporal se asimila cada vez más a la escala local y la escala universal al poder espiritual. La ruptura medieval con la polis clásica, si nuestra tesis es correcta, opera de modo pleno a nivel del poder temporal local, y de modo impropio en el ámbito del poder temporal universal, ya que a la sazón el Imperio está en proceso de ser completamente reabsorbido por la Iglesia, de acuerdo a la interrelación teórica y al proceso histórico que ya hemos caracterizado. No es casual que el texto en el cual Habermas centra su análisis es un texto específicamente referido a la monarquía, de suyo local: se trata de De Regno, no De Imperio. En La monarquía, cuando Tomás piensa en el poder temporal, no considera tanto al Imperio sino precisamente a los reinos locales. El Imperio forma un sistema con la Iglesia, los dos poderes universales de la Roma medieval.

\section{Comentarios finales}

La lectura propuesta se puede inscribir en una tesis más amplia referida a cómo el cristianismo preparó accidentalmente la modernidad. Considero que no es tan apropiado ver una protomodernidad o un orden protoburgués en la Edad Media, como sugiere Bertelloni, sino entender que la modernidad es resultado de la escisión de un elemento que en la Edad Media estaba amalgamado con un componente teológico. El pensamiento medieval absorbió el contenido político de la concepción clásica y lo desplazó a un plano teológico. Tras las rupturas que inauguran la modernidad, desaparecidos de escena los poderes universales y la argumentación teológica que los fundamentaban, resta el Estado moderno despolitizado, asociación contractual de intereses individuales. Pero en el medioevo la politicidad no desaparece, sino que queda proyectada a un plano sobrenatural. Si Tomás es protomoderno, como pretende Bertelloni, lo es por accidente.

En algún sentido, la modernidad se prepara en el punto crítico en que el programa gregoriano se cumple acabadamente. En el "instante" en que se restablece por completo en la Edad Media cristiana el modelo de gobierno de la Roma antigua se verifican simultáneamente los siguientes "hechos": 1) La continuidad con la Roma antigua pierde cualquier resto de latencia y se hace explicita, pierde su carácter sim-

Ibidem, p. 72. 
bólico y se torna concreta y efectiva; 2) El sistema de doble poder se desarticula por la reducción completa del orden temporal al espiritual; 3) La Iglesia cristiana se visibiliza, se historiza y se mundaniza por completo; 4) El ciclo de Roma se agota y llega a su fin, ya que la condición de posibilidad de subsistencia de una Roma medieval era su inserción en la tensión escatológica introducida por el cristianismo; 5) Se crean en ese mismo instante las condiciones para una eventual reacción espiritualista, ya que la Iglesia no puede historizarse por completo, es decir, el cristianismo no puede ser tal si se suprime la tensión escatológica que le es inherente; dicha reacción se incubará contra Roma precisamente en el pulmón germánico de occidente; 6) La posibilidad misma de una estructura de gobierno universal queda superada: subsistirá solamente la posibilidad de un Estado local secularizado y despolitizado ya que el componente político fue absorbido y sublimado por aquella estructura de poder legitimada por vía teológica. El resultado final del ciclo de Roma muestra que una Cristiandad o Iglesia-Imperio como proyecto de historización y arraigue acabado del cristianismo en el mundo se revela como un proyecto imposible. Puede subsistir solo como ideal, ya que en el mismo momento en que se concrete debe caducar, pues se muestra necesariamente como una desnaturalización del espíritu cristiano por suprimir aquella tensión escatológica que lo define. El resultado final de este proceso será un nuevo desdoblamiento pero ya sin posibilidad de armonización en un sistema total. Tendremos por un lado un Estado secularizado y por otro un cristianismo espiritualista y desencarnado.

En la modernidad ya no habrá imperio sino el residuo del imperio: el individuo responsable de gestionar para sí la consecución de un fin último ya indeterminado, porque la teología ha hecho silencio. Para Aristóteles el individuo separado de la polis no existe, éste forma una totalidad natural con ella. Como hemos visto, el imperio rompe la totalidad natural de la polis atomizándola en individuos para reconducirlos a una unidad universal superior ${ }^{25}$. En ese sentido, el prolongado ciclo de Roma, desde la antigua a la medieval, no ha hecho otra cosa que preparar el advenimiento del individuo moderno, desprovisto ya de aquella matriz universal que fue condición de posibilidad de su surgimiento. En la modernidad, aquella perfección ético-racional del animal político quedará completamente sublimada en la ética kantiana. El "reino de los fines" kantiano parece una última espiritualización de la Ciudad de Dios medieval, como ésta fue un proyecto de historización del Reino de Dios neotestamentario. De hecho, en Sobre la paz perpetua aparece ya superada la ilusión de la posibilidad de construcción de un poder político universal. No es posible un Estado universal o Imperio, sólo una federación de Estados particulares para garantizar la paz. Un supuesto poder universal se revela en Kant como un poder local con dominio despótico sobre otros poderes locales. Esto es precisamente lo que fue el papado en el período plenomedieval. La paz perpetua no es viable por la constitución de una monarquía universal (como queda demostrado por el fracaso histórico medieval) sino por una federación donde las diversas fuerzas entren en equilibrio. No es posi-

$25 \quad$ Hegel da cuenta en su Filosofía de la Historia Universal de este poder solvente del imperio: “Así como, cuando el cuerpo físico se corrompe, cada punto empieza a tener una vida propia, aunque es solamente la miserable vida de los gusanos, de igual modo se disolvió el organismo del Estado en los átomos de las personas privadas. Esta es ahora la situación de la vida romana: ya no vemos un cuerpo político, sino un señor y muchas personas privadas. El cuerpo político es un cadáver en putrefacción, lleno de apestosos gusanos; y estos gusanos son las personas privadas. Por lo demás, la libertad personal tiene por base este derecho privado romano" (Hegel, Filosofia de la Historia Universal, vol. II, Buenos Aires, Losada, 2009, p. 285). 
ble un derecho público universal, sólo un derecho cosmopolita de carácter limitado ${ }^{26}$. En definitiva, la modernidad representa el vaciamiento de todo contenido político del orden social junto con la imposibilidad de reconstruir poder universal alguno. En este sentido, la modernidad puede distinguirse netamente del período clásico y medieval, razón por la que cualquier anticipación protomoderna en teorías políticas previas debería considerarse accidental.

En esta presentación nos propusimos mostrar los argumentos de Bertelloni en torno a la posibilidad de una ruptura del pensamiento político medieval respecto del clásico y un consecuente anticipo en él de concepciones modernas. La tesis defendida por el citado autor estipula un súbito proceso de despolitización que preanuncia la economización del Estado moderno. Por nuestra parte ofrecimos una interpretación del desarrollo histórico que hizo posible la constitución de un sistema de doble poder universal durante el período medieval como continuidad con el formato de gobierno antiguo. La lectura de La monarquía sugerida para complementar la tesis de Habermas-Bertelloni apunta a vincular el hecho histórico de la constitución de un doble poder con el fenómeno teórico mencionado relativo a la despolitización del orden temporal. Sugerimos una cierta continuidad entre el pensamiento político clásico y medieval en la medida en que puede rastrearse el componente político de la polis clásica sublimado a un plano teológico, con objeto de legitimar el sistema de doble poder medieval. Encontramos consecuentemente que es más conveniente hablar de un anticipo protomoderno de carácter accidental en el pensamiento político medieval.

26 Cf. Kant, Sobre la paz perpetua, Madrid, Tecnos, 1998, pp. 21-27. 